\title{
Patents on Computer-Related Inventions in India
}

\section{Guido Noto La Diega*}

Northumbria University; President of 'Ital-IoT'; cultore della materia in diritto privato and diritto d'autore at the Università degli Studi di Palermo, UK

\begin{abstract}
In India, sec. 3(k) of the Patents Act 1970 clearly excludes the patentability of computer programmes per se. For many years, the regime of computer-implemented inventions has been unclear, until the Controller General of Patents, Designs and Trade Marks (the Indian homologous of the Intellectual Property Office) issued its Guidelines on the examination of computer-related inventions. Notably, this gave rise the civil society's protests; indeed, there was the fear that the government was surreptisciously allowing the patentability of computer programmes per se. Therefore, the guidelines have been withdrawn and recently a new version has been published. It openly reaffirms the exclusion of the software patents and introduces a three-step test to determine the applicability of sec. $3(\mathrm{k})$ of the Patents Act to computer-related inventions. This opinion focuses the new guidance, by placing it in the context of the leading role of India in the technological and social developments revolving around the Internet of Things.
\end{abstract}

Keywords: Computer-related inventions; India; Internet of things; Computer programs; Patentability

\section{Introduction}

Developing countries like India (recently re-labelled by the World Bank as "lower middle income country) have always been a complicated relationship with intellectual property. Most developing countries claimed, quite sensibly, that intellectual property is a typical western white capitalistic tool used to oppress and colonise countries below the Brandt line.

To oppose strong intellectual property regimes, therefore, has been a way to fight (cultural and economic) imperialism. Moreover, it has been a practical way to enable development, for instance, by importing medicines and developing low cost substitutes, notwithstanding the patent protection.

However, India is also an incredibly creative country and it is not surprising that at some point the Government has decided to increase the protection of intangible assets, including traditional methods such as Ayurveda, Unani, Siddha and Yoga. Anyway, even though the number of patent filings has increased in the last few years, "the percentage of filings by Indians is relatively low" [1], thus suggesting that, at least to some extent, intellectual property is still a tool controlled by foreigners. Indeed, [1] has shown how the development of the patent policies in India has been influenced by the pressures exerted by the United States.

According to me, the two main expressions of the new Indian path towards the propertisation of the immaterial (i.e. commodification of knowledge) are, on the one hand, the new guidelines on the examination of computer related-inventions (CRIs) of February 2016 and the National Intellectual Property Policy of May 2016.

This article focuses on the former, therefore let us only say that the latter set forth clear steps to strengthen intellectual property rights in India, to make of it "a TRIPS compliant, robust, equitable and dynamic IPR regime" $[1,2]$.

With particular regards, to the pharmaceutical sector, the steps to be taken to commercialise intellectual property rights include:

i. "Ensure enhanced access to affordable medicines and other healthcare solutions by (a) encouraging cross-sector partnerships between public sector, private sector, universities and NGOs; (b) promoting novel licensing models, and (c) developing novel technology platforms" (Ministry of Commerce and Industry Department of Industrial Policy and Promotion, 2016, 5.8).

ii. "Make efforts to reduce dependency on active pharmaceutical ingredients (API) imports, including incentivizing manufacture of APIs in India and revitalizing public sector undertakings in health care sector"; (Ministry of Commerce and Industry Department of Industrial Policy \& Promotion, 2016, 5.10).

This could be considered as the response to the fact that the Office of the United States Trade Representative, in its last report, has kept India in the priority watch list of countries with unfavourable practices, with particular regard to its patent protection. It is interesting that the Office suggests that up to 20 percent of drugs sold in India are counterfeit and, allegedly, the reason why India is kept in the priority watch list is because counterfeit medicines "could represent a serious threat to patient health and safety [3].

The complicated relationship between India (and Indians) and intellectual property is well illustrated by the evolutions regarding CRIs. We will see below that, against a statutory provision clearly prohibiting pure software patents, the Government adopted some guidelines that were purely worded, in that it could seem that thenceforth computer programs per se would have been eligible for patent protection (like the United States and unlike Europe). The guidelines have the subject of harsh criticism, because the patentability of software was seen as contrary to the public interest. In particular, it risked to stifle innovation in the strong and dynamic software industry and it would have been contrary to the "openness" policy of favouring free and open source software [1].

This article is the outgrowth of the adoption of the final version of the Indian guidelines on CRIs, which have been surprisingly overlooked

*Corresponding author: Noto La Diega G, Lecturer in Law at the Northumbria University; President of 'Ital-loT', Visiting Lecturer in Private Law and Copyright Law at University Of Palermo, UK, Tel: +44(191)2326002; E-mail: guido.diega@northumbria.ac.uk

Received October 21, 2016; Accepted November 11, 2016; Published November 28, 2016

Citation: Noto La Diega G (2016) Patents on Computer-Related Inventions in India. Intel Prop Rights. S1: 009. doi: 10.4172/2375-4516.S1-009

Copyright: (c) 2016 Noto La Diega G. This is an open-access article distributed under the terms of the Creative Commons Attribution License, which permits unrestricted use, distribution, and reproduction in any medium, provided the original author and source are credited. 
in the legal literature. As an Internet of Things (IoT) scholar, I foresee that the era of interconnected devices we live in will lead to a dramatic increase of applications for software patents and if examiners, courts, and legislators will not be careful, there is the concrete risk of a surreptitious generalised grant of patents for computer programs per se. The clarity provided by the Indian guidelines, following a lively public debate, can constitute good practices that Europe and the United States should take into account [4].

\section{Delving into Computer-related Inventions}

A computer-related invention (or computer-implemented invention, CII, in the European formulation) involves the use of a computer, computer network or other programmable apparatus, where one or more features are realised wholly or partly by means of a computer program. CRIs and CIIs are a critical topic in patent law, since a too relaxed approach in awarding grants for this kind of inventions may risk allowing a double protection for computer programs: copyright and patents. Thus, a too much broad monopoly would be legitimised, with a subsequent increased propertisation of intangibles. A similar problem can occur in the United States, notwithstanding the patentability of computer programs per se. There the risk is the eligibility for protection of mere abstract ideas.

Mischievous commentators may argue that the CIIs are a surreptitious way to obtain a double binary for software protection. This may become true with the IoT. Indeed, with the gradual substitution of old products with smart devices, we will face an unprecedented growth of CIIs; therefore, asserting that computer programs are not patentable in Europe may sound hypocritical. In other terms, I foresee that most of the computer programs will be embedded in smart devices, with the consequential patentability of most computer programs under the label of CII.

The impact of the IoT on patents can be observed also from another point of view. I believe that the IoT provokes a redefinition of the concepts of novelty and originality for purposes of assessing patentability, essentially because of two characteristics: (a) network structure: patentability may increasingly derive from the way smart devices interact; (b) composite nature of the said devices: novelty might stem from the way the components of a single device interact.

As to the first aspect, the customers are more and more interested to the novel interaction between their devices, rather than to the device in isolation (let us think a hub in a domotics context). Interoperability and open standards are the way forward, even though security plays often the role of excuse to build closed sub-systems, thus giving rise to the "Internet of Silos".

When it comes to the composite nature of devices, it means that usually devices incorporate several other devices. A smartphone contains a large number of sensors and damage may occur because of a defect or inaccuracy of any of the said components of the device. It is not always clear if the liability should fall on the main actor responsible for the composite device or if its component's actors should be liable. Generally speaking, and unless a contrary evidence is provided, I am in favour of the first hypothesis, for at least two reasons.

Firstly, the final manufacturer has a duty to double-check the security and safety of the composite device both when placing it on the market and during the provision of the services. Secondly, it could prove impossible for the customer to track the supply chain and find the responsible for the single sub-thing. The conclusion may be different depending on the openness or closure of the system (e.g. Apple can control third-parties' apps through its store, whereas Android stores are open, thus not allowing the same control). Courts may also give some relevance to the number of sub-things present in the composite thing (an airplane is not the same as a light bulb) and the kind of activity for which the device is used (a defibrillator can save a life and therefore higher standards of security and a stricter scrutiny are required) [5].

\section{India at the Forefront of Innovation in Asia}

It is not sufficiently known that India has a pioneering role in the development of new technologies and new approaches to the concept itself of innovation.

A notable example is Ministry of Electronics \& Information Technology [6] which builds on the 'Digital India Programme.' In issuing it, the Department of Electronics and Information Technology ('DeitY') pursued four goals. Firstly, to create an IoT industry in India of USD 15 billion by 2020 (with a share of 5-6\% of global IoT industry.) Secondly, to undertake capacity development for IoT specific skill-sets for domestic and international markets. Thirdly, to undertake R\&D for all the assisting technologies. Lastly, to develop smart devices specific to Indian needs in all possible domains. The policy has been seen by Aggarwal [7] as the realisation of the "Zero Defect Zero Effect" slogan, which was coined by Prime Minister of India, Narendra Modi. Part of the Make in India strategy, it denotes manufacturing mechanisms whereby the possibility of error and the environmental impact are, or should be, eliminated. Malevolent commentators may judge it as a 'green washing' policy in order to convince transnational corporations to manufacture their products in India and to increase the exportations. In fact, in the Independence Day speech, Modi had said that the 'zero defect, zero effect' policy was critical so that "our exported goods are never returned to us" [8]. However, the reasons for the policy will prove to be of secondary importance, as long as the implementation activities will be carried out with the bottom-up inclusive approach that we are seeing in the deployment of the Indian smart cities plan, as in Ministry of Urban Development [9].

Future research shall focus on the risks of such a fast growth. For instance, in 2010, the Government of India (better said, the Unique Identification Authority of India, 'UIDAI') has started collecting biometric data (mainly fingerprints and iris signatures) as a condition to issue the so-called Aadhaar number and card. Without the number, one cannot apply for subsidies. The UIDAI has already collected the biometric data of nearly a billion people [10]. On 25 March 2016, the Aadhaar (Targeted Delivery of Financial and Other Subsidies, Benefits and Services) Act, 2016 has received the assent of the President. The Act provides federal agencies with the right to access the said database in the interest of national security. There is the actual risk of using the largest biometric database in the world for surveillance purposes.

\section{The Guidelines on the Examination of Computer-related inventions. Historical Background, Basic Concepts and the (not always Savvy) Protests of the Civil Society}

India, unlike the US, is following the double-binary European approach. Indeed, s.3(k) of the Patents Act 1970 states that a "computer programme per se" is not patentable, but until recently it was not clear whether CRIs were excluded from the subject matter or not. The silence kept on CRIs will not surprise who knows that the Patents Act, notwithstanding its amendments, remains an old act, as shown inter alia by the several provisions on floppy disks.

The path towards the introduction of software patents had been 
gradual and Brownian. In 2002, the Patents (Amendments) Act, 2002 introduced the words 'per se' in s.3(k) of the Patents Act. This was explained by the Joint Parliamentary Committee by saying that "sometimes the computer program may include certain other things, ancillary thereto or developed thereon. The intention here is not to reject them for grant of patent if they are inventions. However, the computer programs as such are not intended to be granted patent" [11]. The first guidance explained 'ancillary' by referring to "things which are essential to give effect to the computer program."

The second step was the Patents (Amendment) Ordinance, 2004. At that time, an amendment to provide for the patentability of computer programs insofar as they enhanced technology was rejected by the Lok Sabha and the Rajya Sabha (the houses of the Parliament of India), "as they feared that this would be beneficial only to multinational companies" [12].

A similar failed attempt was made by the Patents (Amendment) Bill, 2005 that sought to extend patentability to computer programs with "technical application to industry". The 'transnational corporations' exception was successfully raised again.

In 2011, then, the Controller General of Patents, Designs and Trade marks (hereinafter the 'Controller', the Indian homologous of the Intellectual Property Office) clarified that "claims directed at 'computer program products' are computer programs per se stored in a computer readable medium and as such are not allowable" [13]. Moreover, when a claim inter alia contains a subject matter that is not limited to a computer program, "it is examined whether such subject matter is sufficiently disclosed in the specification and forms an essential part of the invention" [13].

It is notable that the draft CRI guidelines published in 2013 were clear as to the exclusion of any computer program that may work on any general-purpose computer or "related device" (mainly smart devices) did not meet the requirements of law [14].

In August 2015, the Controller issued the first CRI guidance; it allowed the patenting of programs, which demonstrated technical advancement. Unsurprisingly, the guidance gave rise to protests of the civil society. Many organisations and citizens, indeed, complained about the contrast with s.3(k) of the Patents Act and because software patentability was seen as a break to innovation [15]. To be precise, the guidance reaffirmed that computer programs per se were excluded from patentability and, therefore, "[c]laims which are directed towards computer programs per se are excluded from patentability"; consequently, the citizens' claims that computer programs were excluded "unconditionally" and that the one at issues was a "blanket exclusion' were not entirely correct. Moreover, for being considered patentable, the subject matter should involve either "- a novel hardware, or - a novel hardware with a novel computer program, or - a novel computer program with a known hardware which goes beyond the normal interaction with such hardware and affects a change in the functionality and/or performance of the existing hardware." The 'physical' element looked critical, but the third category presented some ambiguity. In addition, the attached clarification was not helpful (also, it was not clear if it was a clarification or a fourth category): a computer program, "when running on or loaded into a computer, going beyond the 'normal' physical interactions between the software and the hardware on which it is run, and is capable of bringing further technical effect may not be considered as exclusion under these provisions" [16]. The letter of the civil society complained that the patentability of software was maintained dependent on the industrial applicability. This is not precise. Whereas the cited patentability as a result of technical effect could be tricky, the guidance limited itself to state that " $[\mathrm{t}]$ he examination procedure of patent applications relating to CRIs is the same as that for other inventions to the extent of consideration of novelty, inventive step, industrial applicability, sufficiency of disclosure and other requirements under the Patents Act and the rules made thereunder."

After the said protests, with order No. 70 of 2015, the Controller announced that the criticised guidance was to be "kept in abeyance till discussions with stakeholders are completed and contentious issues are resolved." The discussions have been completed and the contentious issues resolved on 19 February 2016, when the Controller published the new guidelines on the examination of CRIs [17]. CRIs now comprise "inventions which involve the use of computers, computer networks or other programmable apparatus and include such inventions having one or more features of which are realized wholly or partially by means of a computer program or programs." Incidentally, one may note that 'other programmable apparatus' is a flexible concept indeed capable to encompass smart devices. The pendant of this notion is the 'computer system', which, under the Information Technology Act, 2000 is "a device or collection of devices, including input and output support devices and excluding calculators which are not programmable and capable of being used in conjunction with external files, which contain computer programs, electronic instructions, input data and output data, that performs logic, arithmetic, data storage and retrieval, communication control and other functions." A very 'IoT' dictionary. Even before that, the definition of 'computer' is sufficiently flexible to accommodate the IoT specific characteristics. The term 'computer' is defined in The Information Technology Act, 2000 as "any electronic, magnetic, optical or other high-speed data processing device or system which performs logical, arithmetic, and memory functions by manipulations of electronic, magnetic or optical impulses, and includes all input, output, processing, storage, computer software, or communication facilities which are connected or related to the computer in a computer system or computer network."

The new guidelines reaffirm the exclusion of the software patents and introduces a three-step test to determine the applicability of s.3(k) of the Patents Act to CRIs. Indeed, "[e]xaminers may rely on the following three stage test in examining CRI applications: (1) Properly construe the claim and identify the actual contribution; (2) If the contribution lies only in mathematical method, business method or algorithm, deny the claim; (3) If the contribution lies in the field of computer program, check whether it is claimed in conjunction with a novel hardware and proceed to other steps to determine patentability with respect to the invention." (Guidelines 2016, s.5) Therefore, if the hardware is not novel (e.g. some innovative smart device), then no patent will be granted. It would seem, consequently, that computer programs running on traditional computers should be excluded by the subject matter of patents. This is particularly clear if one reads the previous version of the guidelines, which included the eligibility of "a novel computer programme with a known hardware which goes beyond the normal interaction with such hardware and affects a change in the functionality and/or performance of the existing hardware".

Moreover, even though the phases of the examination procedure of CRIs are the same as the other inventions as to novelty, inventive step, industrial applicability and sufficiency of disclosure, "[t]he determination that the subject matter relates to one of the excluded categories requires greater skill on the part of the examiner." While explaining that these concepts apply equally to ordinary inventions and 
to CRIs, the Controller specifies that the "determination of industrial applicability in case of CRIs is very crucial since applications relating to CRIs may contain only abstract theories, lacking in industrial application." Furthermore, it explains how the sufficiency of disclosure applies to CRIs. The said requirement means that the invention has to be described "fully and particularly" ('what') and the specification has to explain the best method of operation. Under para. 4.4.2 of the new guidance, "[t]he best mode of operation and/or use of the invention shall be described with suitable illustrations. The specification should not limit the description of the invention only to its functionality rather it should specifically and clearly describe the implementation of the invention.

Even though the use of 'may' might suggest a certain scope for the examiners' discretion and one would have expected that the excluded subject matter should have to be interpreted in a stricter way (as opposed to require "greater skill"), the wording is adamant in linking the patentability of CRIs to inventions which constitute an inextricable mixture of software and (novel) hardware; that is to say, to smart devices. From this point of view, the new CRI guidance may be a formidable input to the developments of IoT inventions, now supported by legal clarity and certainty. Moreover, as a policy recommendation and in consideration of the foreseen growth of CIIs due to the IoT, the European Patent Office may want to be inspired by the Indian guidelines to update and deepen its out-of-date and insufficiently thorough guidance. A first commendable step has been the publication of the $8^{\text {th }}$ edition of Case Law of the Boards of Appeal of the European Patent Office in July 2016, but some ad-hoc guidelines would be more appropriate [18].

\section{Conclusions}

With the advent of the IoT, applications for software patents disguised as CIIs will increase substantially in India. A too strong patent regime for computer programs, in a moment when software is being embedded in most traditional devices, risks not to take into account the trade-off between remuneration of the investments and public good. Moreover, the prevalence of proprietary models can jeopardise interoperability, which is at the very heart of the IoT. There are some good practices to be followed and India's example is to be taken into account, even though the United States do not seem to appreciate it. Indeed, it has been commented that the analysed guidelines would introduce unpredictability for patent applicants and that they have been issued "following an opaque process for soliciting comments" I beg to differ, for the reasons pointed out above. After the civil society has (maybe too) harshly criticised the first version of the guidelines on the CRIs, the Government has revised them in order to make clear that in no way CRIs will be a surreptitious way of granting software patents. This collaboration between lawmakers and civil society has to be saluted and, in the matter at hand, it may have ensured the full unleashing of the IoT full potential.

\section{Acknowledgments}

Thanks to the anonymous reviewers for the useful comments. The responsibility of this article, however, is solely mine.

\section{References}

1. Ministry of Commerce and Industry Department of Industrial Policy \& Promotion (2016) National Intellectual Property Rights Policy.

2. Medecins Sans F (2015) A timeline of U.S. attacks on India's patent law \& generic competition.

3. Office of the United States Trade Representative (2016) 2016 Special 301 Report.

4. Noto L, Diega G (2016) Software patents and the Internet of Things in Europe the United States, and India. European Intellectual Property Review.

5. Noto L, Diega G (2016) Clouds of Things: Data Protection and Consumer Law at the Intersection of Cloud Computing and the Internet of Things in the United Kingdom. Journal of Law \& Economic Regulation 9: 69-93.

6. Ministry of Electronics \& Information Technology (2015) Draft Policy on Internet of Things.

7. Aggarwal V (2015) India's first Internet of Things policy to focus on Zero Defect Zero Effect. The Economic Times India.

8. Modi N (2014) Prime Minister Narendra Modi's speech on 68th Independence Day.

9. Ministry of Urban Development (2015) Smart cities. Statement and Guidelines.

10. Miglani S, Kumar M (2016) India's billion-member biometric database raises privacy fears.

11. Comments and recommendations on the Guidelines for Examination of Computer-Related Inventions (CRIs) (2015).

12. Chathurvedula S (2015) Revised guidelines for software patents put on hold Live Mint.

13. Office of Controller General of Patents, Designs \& Trademarks (2011). Manual of Patent Office Practice and Procedure 1: 11.

14. Choudhary K (2013) Draft Guidelines for Examination of Computer Related Inventions. Office of Controller General of Patents, Designs and Trademarks.

15. Concerns over the Guidelines for Examination of Computer Related Inventions (CRIs) (2015)

16. Office of Controller General of Patents, Designs and Trademarks (2013). Draft Guidelines for Examination of Computer Related Inventions.

17. Office of the Controller General of Patents, Designs and Trade marks (2016) Guidelines for Examination of Computer Related Inventions (CRIs).

18. Mohan V (2014) Ecologists cheer Modi's 'zero defect, zero effect' slogan. The Times of India. 